\title{
FACTORS INFLUENCING ACTUAL USE OF MOBILE LEARNING CONNECTED WITH E-LEARNING
}

\author{
Young Ju Joo ${ }^{1}$ Sunyoung Joung ${ }^{2}$ Eui Kyoung Shin ${ }^{3}$ Eugene Lim ${ }^{4}$ and \\ Miran Choi ${ }^{5}$ \\ 1,3,4,5 Department of Education, Ewha Womans University, Seoul, South Korea \\ youngjudewha.ac.kr \\ luvsiin@naver.com \\ lim_u@naver.com \\ bohemiranenaver.com \\ ${ }^{2}$ Department of Education, Kookmin University, Seoul, South Korea \\ sjoung@kookmin.ac.kr
}

\begin{abstract}
The purpose of the current study is to propose discriminated management strategies for mobile learning environments after observing the effects of mobile self-efficacy on performance expectancy and effort expectancy, the social influence on intention of use, and the effects of facilitating conditions and intention of use on learners' actual use of mobile learning by adding mobile self-efficacy to the UTAUT model proposed by Venkatesh et al. (2003). We established hypotheses to determine whether mobile self-efficacy, performance expectancy, effort expectancy, social influence, and facilitating conditions affect intention of use and whether intention of use affects actual use. Results showed that when mobile self-efficacy and performance expectancy is higher, so is the intention of using mobile learning services. It was confirmed that the factors had significant indirect effects on the actual use by mediating the intention of use and that the intention of use directly affected actual use. However, the current research reported that effort expectancy, social influence, and facilitation conditions did not have significant effects on the intention of using mobile learning services. These results will contribute substantially to the design of effective mobile learning environments.
\end{abstract}

\section{KEYWORDS}

Structural relationship, Technology Acceptance Model, Mobile learning

\section{INTRODUCTION}

Despite the tendency of cyber-universities to offer many services, e-learners are likely to limit their mobile learning to services within the administrative context, such as announcements. Actual use of mobile services connected with e-learning is insufficient (Lee, 2010). Learners in traditional as well as cyber-universities identify the complexity of log-in and authentication processes, speed problems due to simultaneous access, and limitations from unstable functions as factors inhibiting the use of mobile learning services (Min, Sin, Ryu, \& Gwak, 2014).

It was discovered that the current level of mobile learning practice consists simply of converting e-learning contents to mobile learning contents. Learners satisfied with using e-learning do not

David C. Wyld et al. (Eds) : SAI, CDKP, ICAITA, NeCoM, SEAS, CMCA, ASUC, Signal - 2014 pp. 169-176, 2014. (C) CS \& IT-CSCP 2014

DOI : $10.5121 /$ csit.2014.41116 
dare to switch to mobile learning (Choi \& Rho, 2014). Accordingly, it is necessary to devise strategies to increase mobile learning service adoption by analyzing the factors that increase practical use of mobile learning to expand the usage of mobile learning.

Although several theories have been devised to predict the adoption and diffusion of new technology, such as the Theory of Reasoned Action (TRA), the Technology Acceptance Model (TAM), it is necessary to develop an integrative theory and model for the adoption and diffusion of new technologies because of individual differences in technology adoption and the heterogeneity of research environments(Venkatesh, Morris, Davis, \& Davis, 2003). Venkatesh and his colleagues (2003) proposed a Unified Theory of Acceptance and Use of Technology (UTAUT) Model that integrates the eight current models after reexamining the validity. The UTAUT is used as the latest model for analyzing intention of using new technology and actual use. The eight models are the TRA, TAM, Theory of Planned Behavior (TPB), Technology Acceptance Model-Theory of Planned Behavior (TAM-TPB), Integrated Model of Technology Acceptance and Use, Motivation Model, PC Utilization Model, Diffusion of Innovation Theory, and Social Cognition Theory (Venkatesh et al., 2003).

The UTAUT model is well known to affect performance expectancy, effort expectancy, social influence, and facilitating conditions. Among them, performance expectancy and effort expectancy directly affect social influences, and facilitating conditions and intention of use affect actual use (Venkatesh et al., 2003). Meanwhile, Venkatesh and his colleagues (2003) referred to self-efficacy as a variable directly affecting actual use in conjunction with facilitating conditions and intention of use. They excluded self-efficacy from the final model because of the postresearch results, which proved the non-significant effects of self-efficacy on actual use (Venkatesh \& Zhang, 2010).

However, recent empirical studies (Chiu \& Wang, 2008; El-Gayar \& Moran, 2006; Luarn \& Lin, 2005) have reported self-efficacy as directly affecting actual use of new technologies and intention of using information systems. There are contradictory research results between selfefficacy and actual intention in the mobile learning environments. Therefore, we will examine the effects of mobile self-efficacy by adding it as an individual variable in the mobile learning environments connected with e-learning.

The purpose of current study, then, is to propose discriminated management strategies for mobile learning environments after observing the effects of mobile self-efficacy on performance expectancy and effort expectancy, the social influence on intention of use, and the effects of facilitating conditions and intention of use on learners' actual use of mobile learning by adding mobile self-efficacy to the UTAUT model proposed by Venkatesh et al. (2003)

We established hypotheses to determine whether mobile self-efficacy, performance expectancy, effort expectancy, social influence, and facilitating conditions affect intention of use and whether intention of use affects actual use. The research hypotheses are as follows, and the hypothetical research model is displayed in Figure 1.

[Hypothesis 1] Mobile self-efficacy, performance expectancy, effort expectancy, and social influence will affect intention of mobile learning.

[Hypothesis 2] Intention of mobile learning will affect the actual uses of mobile learning. 


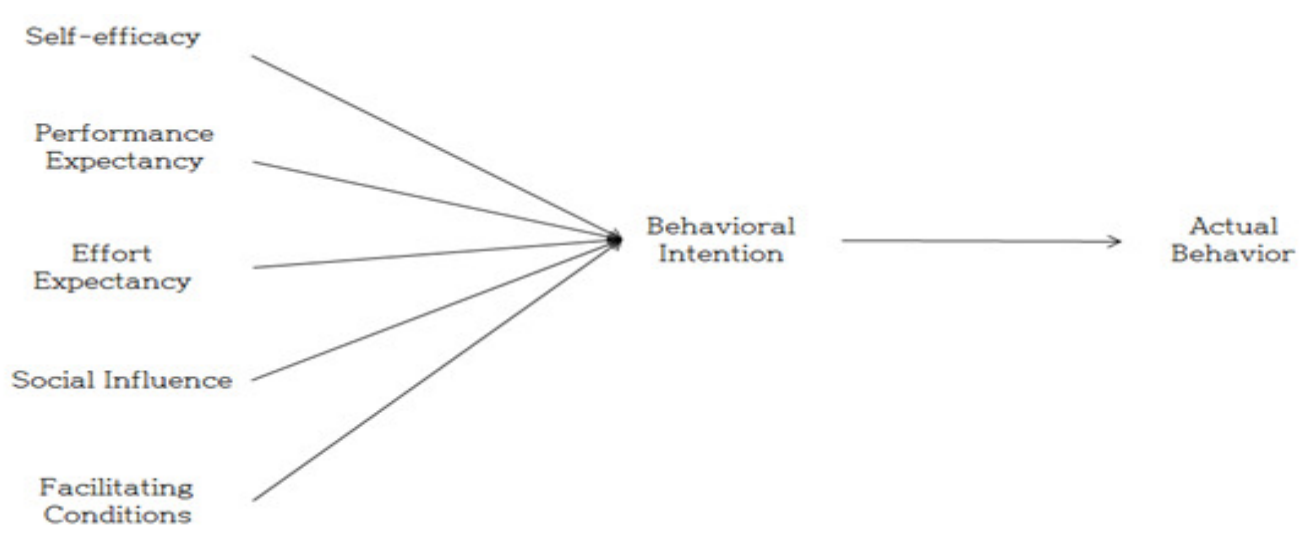

Figure 1. Hypothetical Research Model

* Self-efficacy = Mobile self-efficacy

\section{RESEARCH METHOD}

\subsection{Subjects and Research Procedure}

Research subjects were undergraduate students registered for the required course majoring in health wellness at a $\mathrm{W}$ cyber university. The W Cyber University provides Wellness Health Programs specialized in Korean culture and practical welfare through mobiles services by both IOS and Android platforms. Subjects were a total of 238 people. Male subjects were $80(33.6 \%)$ and female ones were $158(66.4 \%)$. Subjects in their 20s were eight $(3.4 \%)$, 30s were $32(13.4 \%)$, 40 s were $105(44.1 \%)$, 50s were $84(35.7 \%)$, and over 60 s were $8(3.4 \%)$. Mostly were in their 40 s and 50s.

\subsection{Measurement Instrument}

The instrument used in this study contains 28 self-report items including mobile self-efficacy, performance expectancy, effort expectancy, social influence, facilitating conditions, intention of use, and actual use of mobile services. Each item was revised appropriately to meet the current research purpose after content validity tests were conducted by two experts. All variables except actual use were measured on a five-point Likert scale; actual use was measured using actual access time. Each variable was assessed using the measures described below:

To measure mobile self-efficacy, we used the instrument developed by Wang and Wang (2008), which consists of ten questions asking about self-ability or self-belief related to performing mobile operations. For reliability, the measurement has a Cronbach's $\alpha$ of .92 . To measure performance expectancy, effort expectancy, social influence, facilitating conditions, and intention of use, we used the instrument by Venkatesh et al. (2003), which consists of three items asking about expecting usefulness, productivity improvement, expenditure reduction, and performance improvement. For reliability, the measurement has a Cronbach's $\alpha$ of .83. Effort expectancy relates to e-learners' perceived ease of use in mobile learning. It was measured through four items with Cronbach's $\alpha$ of .87. Social influence was measured through four items with Cronbach's $\alpha$ of .81. Facilitating conditions is the perceived possibility of receiving help while using mobile learning services. It is measured through four items with Cronbach's $\alpha$ of .80 . Intention of use is the intention of continuously using the mobile learning services. It is measured through three items with Cronbach's $\alpha$ of .96 . Finally, actual use is the degree of actual usage of mobile services. It was measured using actual access time to mobile learning services during a semester. 


\subsection{Research Analysis Methods}

We conducted reliability tests, factor analysis, descriptive statistics, and correlation analysis with the collected data using SPSS. We used structural equation modeling (SEM) to analyze the structural relationships between relevant variables and actual use of mobile learning. To analyze the SEM, we first evaluated the validity of the measurement model by using the AMOS program. After that, we used two approaches in conducting SEM. We used maximum likelihood estimation (MLE) to verify the data normality and confirmed model fit using a $\chi^{2}$ test, TLI, CFI, and RMSEA, which are widely used measures of model fit.

\section{RESEARCH RESULTS}

\subsection{Examination of Measurement Model}

This study examined the validity of the structural model prior to analyzing it. The results are displayed in Table 1 . Observing Table 1 , although the $\chi^{2}$ results of the measurement model were significant $(39, \mathrm{n}=238, \mathrm{CMIN}=71.980)$ at $\mathrm{p}$ level of .001 , it is desirable to assess model fit by using other indices since $\chi^{2}$ is sensitive to sample size and data normality. TLI (.978) and CFI (.987) were both over .90 , satisfying the acceptable criteria, and RMSEA (.060) was also acceptable. Therefore, it was confirmed that the measurement model is suitable.

Table 1. Fit of the Measurement Model $(n=238)$

\begin{tabular}{lcccccc}
\hline & CMIN & P & df & TLI & CFI & $\begin{array}{c}\text { RMSEA (90\% Confidence } \\
\text { Interval) }\end{array}$ \\
\hline $\begin{array}{c}\text { Measurement } \\
\text { Model }\end{array}$ & 71.980 & .001 & 39 & .978 & .987 & $.060(.037 \sim .081)$ \\
\hline $\begin{array}{c}\text { Criteria } \\
\text { Value }\end{array}$ & & & & $* *>.900 *$ & $>.900$ & $<.080$ \\
\hline
\end{tabular}

The results of confirmatory factor analysis provided robust evidence of construct and distinctive validity. Standard factor loadings in each path of the measurement variable ranged from .78 to .98 , both over .50 . This means that the selected index variables, which are selected to measure each theoretical variable in each research model, indicate adequate construct validity (Bagozzi \& Yi, 1988). The results of examining the correlations between latent variables ranged from .47 to .78 , showing low cross-correlations (less than .80 ). This shows that there is sufficient distinctive validity between the latent variables (Bagozzi et al., 1988).

\subsection{Structural Model Examination}

First, as shown in the Table 2, the examination result of $\chi^{2}([50, \mathrm{n}=238]=103.581, \mathrm{p}=.000)$ was significant, and we can consider it an appropriate model with evidence of TLI $=.961, \mathrm{CFI}=$ .979 , and RMSEA $=.067$. This means that there is a causal relationship between mobile selfefficacy, performance expectancy, performance expectancy, social influence, facilitating conditions, intention of use, and actual time for use. 
Table 2. Fit of the Initial Structural Model $(n=238)$

\begin{tabular}{|c|c|c|c|c|c|c|c|}
\hline & CMIN & $\mathrm{P}$ & df & TLI & CFI & $\begin{array}{l}\text { RMSEA } \quad(90 \% \\
\text { Interval })\end{array}$ & Confidence \\
\hline $\begin{array}{l}\text { Initial Structural } \\
\text { Model }\end{array}$ & 103.581 & .000 & 50 & .961 & .979 & .067 (.049 .086) & \\
\hline Criteria Value & & & & $>.900$ & $>.900$ & $<.080$ & \\
\hline
\end{tabular}

We examined the direct effects between variables included in the structural model and estimated the path coefficients under the verification that the structural model has a good fit. As shown in Table 3, three paths among six direct paths are statistically significant.

First, the effect of mobile self-efficacy on intention of use was significant $(\beta=.371, t=4.258, p<$ $.05)$. Second, the effect of performance expectancy on intention of use was significant $(\beta=.734, t$ $=5.852, \mathrm{p}<.05)$. Third, the effect of effort expectancy on intention of use was not significant $(\beta$ $=-.122, t=-1.039, p>.05)$. Fourth, the effect of social influence on intention of use was not significant $(\beta=-.057, t=-.668, p>.05)$. Fifth, the effect of facilitating conditions on actual use was not significant $(\beta=-.104, \mathrm{t}=-1.216, \mathrm{p}>.05)$. Finally, the effect of intention of use on actual use was significant $(\beta=.374, \mathrm{t}=4.177, \mathrm{p}<.05)$.

After examining statistical significance in the initial structural model, the direct effects of performance expectancy, effort expectancy, social influence, and facilitation conditions were found to be not statistically significant. We established a succinct revised structural model under the supposition that there is no significant difference in model fit after removing insignificant paths from the initial structural model. We conducted a $\chi^{2}$ test to confirm if there is a statistical difference between the initial structural model and a revised succinct model since there is a hierarchical relationship between the initial structural and revised succinct models. From the analysis results, we selected the revised succinct research model as a final research model since there was no significant difference between the initial structural model and the revised succinct model $\left(\Delta \chi^{2}=5.933, \mathrm{p}=115\right)$.

Table 3. Examination of Fit of Revised Structural Model $(n=238)$

\begin{tabular}{ccccccc}
\hline & CMIN & P & df & TLI & CFI & $\begin{array}{c}\text { RMSEA (90\% Confidence } \\
\text { Interval) }\end{array}$ \\
\hline $\begin{array}{c}\text { Revised } \\
\text { Structural } \\
\text { Model }\end{array}$ & 109.515 & .000 & 53 & .961 & .978 & .067 (.049 .086) \\
\hline $\begin{array}{c}\text { Initial Structural } \\
\text { Model }\end{array}$ & 103.581 & .000 & 50 & .961 & .979 & $.067(.049 \sim .086)$ \\
\hline Criteria Value & & & & & \\
\hline
\end{tabular}

The results of MLE estimation to measure the fit of the revised structural model are shown in Table 3. The revised structural model had good fit, with TLI $=.961, \mathrm{CFI}=.978$, and RMSEA = .067. Accordingly, the results of investigating the effects of mobile self-efficacy, performance expectancy, facilitating conditions, intention of use, and actual use are shown in Table 4. 
The effect of mobile self-efficacy on intention of use was $\beta=.269(\mathrm{t}=3.844, p<.05)$, that of performance expectancy on intention of use was $\beta=.596(\mathrm{t}=7.697, p<.05)$, and that of intention of use on actual use was $\beta=.373(\mathrm{t}=4.162, p<.05)$.

The research results reported that mobile self-efficacy and performance expectancy affects intention of use, and intention of use affects actual use. The final model including standardized path coefficients is shown in Figure 2.

Table 4. Path Coefficients of Revised Structural Model $\quad(n=238)$

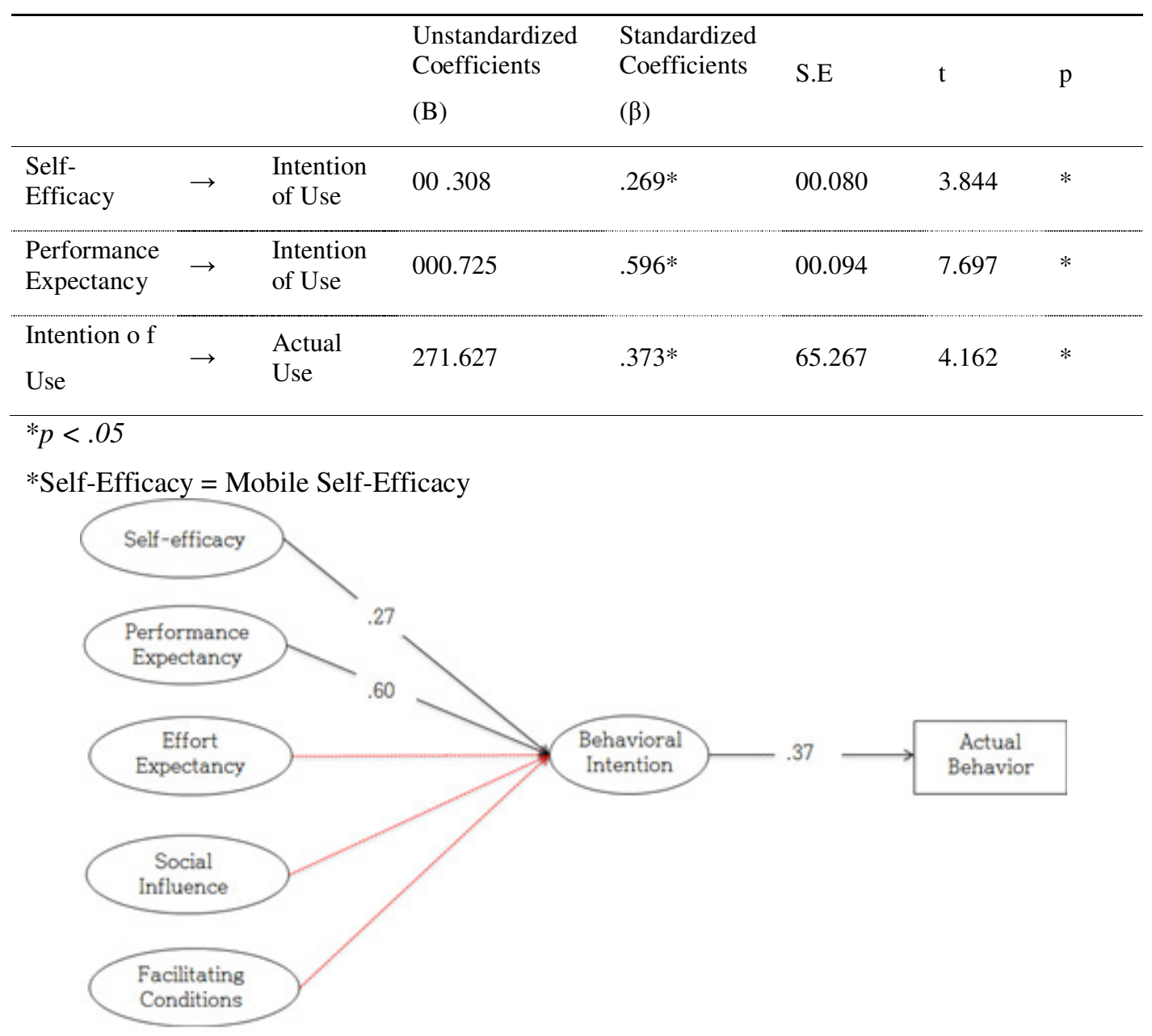

Figure 2. Standardized Path Coefficients of Revised Model

The results show that mobile self-efficacy and performance expectancy affect intention of use, and intention of use affects actual use. Accordingly, we examined the significance of indirect effects between the variables using a Sobel test (Kline, 2011). Mobile self-efficacy $(\mathrm{z}=2.826, p=$ $0.005)$ and performance expectancy $(\mathrm{z}=3.662, p=0.000)$ were found to have indirect effects on mobile learning service by mediating intention of use. These direct and indirect effects are analyzed in Table 5 . 
Table 5. Direct and Indirect Effects Analysis of Revised Structural Model $(n=238)$

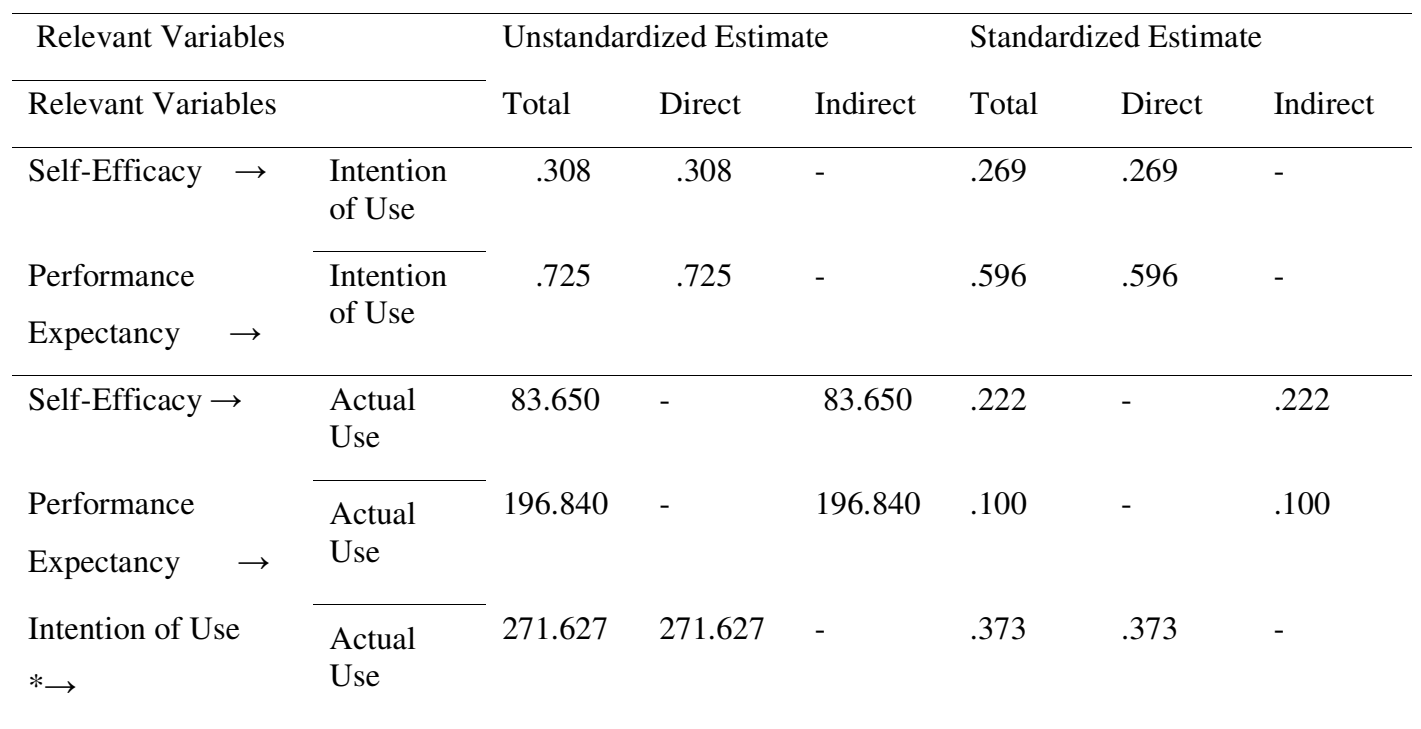

* Self-Efficacy = Mobile Self-Efficacy

\section{CONCLUSIONS AND SUgGeSTIONS}

According to the current research results, when mobile self-efficacy and performance expectancy are high, so is the intention of using mobile learning services. It was confirmed that the factors had significant indirect effects on actual use by mediating intention of use. It was also confirmed that the intention of use directly affected actual use. However, the current research reported that effort expectancy, social influence, and facilitation conditions did not have significant effects on the intention of using mobile learning services.

Firstly, mobile self-efficacy in the use of mobile learning service connected with e-learning. That is, cyber-learners' feelings of self-confidence and self-ability when using mobile machines significantly affected intention of using mobile learning services.

Secondly, it appeared that performance expectancy increased the intention of mobile learning, and mobile learning services connected with e-learning improved learning outcomes, reduced time and expenditure, and increased the efficiency and effectiveness of learning. The current results will contribute substantially to the design of effective mobile learning environments.

\section{ACKNOWLEDGEMENTS}

This work was supported by National Research Foundation of Korea Grant funded by the Korean Government (2012-045331)

\section{REFERENCES}

[1] Bagozzi, R. P., \& Yi, Y. (1988). On the evaluation of structural equation models. Journal of the academy of marketing science, 16(1), 74-94.

[2] Chiu, C. M., \& Wang, E. T. (2008). Understanding Web-based learning continuance intention: The role of subjective task value. Information \& Management, 45(3), 194-201. 
[3] Choi, M. N., Roh, H .L. (2014). A Study of the influence of motivations on the intention of taking mobile-learning courses in universities. The Journal of Educational Information and Media, 20(1), 7795.

[4] El-Gayar, O. F., \& Moran, M. (2006). College students' acceptance of tablet PCs: an application of the UTAUT model. Dakota State University.

[5] Lee, J. (2010). M-Learning as a Challenge for Cyber Universities: The Present and the Future. Journal of Cyber society \& Culture, 1(2), 91-119.

[6] Luarn, P., \& Lin, H. H. (2005). Toward an understanding of the behavioral intention to use mobile banking. Computers in Human Behavior, 21(6), 873-891.

[7] Min, K. B., Shin, M. H., Yu, T. H., Hwak, S. H. (2014). Strategies for Revitalizing E-Learning Through Investigating the Characteristics of E-Learning and the Needs of Distance Learners in the Domestic Universities in Korea. The Korea Contents Society, 14(1), 30-39.

[8] Min, K. B., Shin, M., Shin, Yu, T., Kwak, S. (2014). Strategies for Revitalizing E-Learning through Investigating the Characteristics of E-Learning and the Needs of Distance Learners in the Domestic Universities in Korea. The Korea Contents Society, 14(1), 30-39.

[9] Venkatesh, V., \& Zhang, X. (2010). Unified Theory of Acceptance and Use of Technology: US Vs. China. Journal of Global Information Technology Management, 13(1).

[10] Venkatesh, V., Morris, M. G., Davis, G. B., \& Davis, F. D. (2003). User acceptance of information technology: Toward a unified view. MIS quarterly, 27(3).

[11] Wang, Y. S. \& Wang, H. Y. (2008). Developing and Validating an Instrument for Measuring Mobile Computing Self-Efficacy. Cyber Psychology \& Behavior, 11(4), 405-413. 